The Journal of Laryngology \& Otology

http://journals.cambridge.org/JLO

Additional services for The Journal of Laryngology \& Otology:

Email alerts: $\underline{\text { Click here }}$

Subscriptions: $\underline{\text { Click here }}$

Commercial reprints: $\underline{\text { Click here }}$

Terms of use : $\underline{\text { Click here }}$

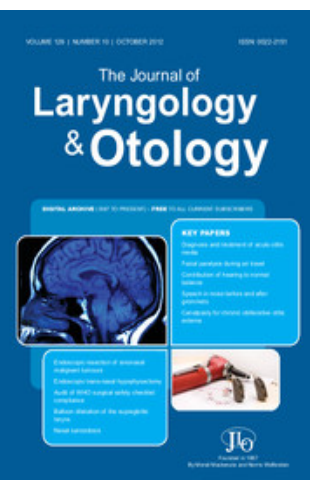

\title{
Unilateral abducens nerve palsy: a presenting sign of sphenoid sinus mucocoeles
}

A. Muneer and N. S. Jones

The Journal of Laryngology \& Otology / Volume 111 / Issue 07 / July 1997, pp 644 - 646

DOI: 10.1017/S0022215100138204, Published online: 29 June 2007

Link to this article: http://journals.cambridge.org/abstract_S0022215100138204

How to cite this article:

A. Muneer and N. S. Jones (1997). Unilateral abducens nerve palsy: a presenting sign of sphenoid sinus mucocoeles. The Journal of Laryngology \& Otology, 111, pp 644-646 doi:10.1017/S0022215100138204

Request Permissions : $\underline{\text { Click here }}$ 


\title{
Unilateral abducens nerve palsy: a presenting sign of sphenoid sinus mucocoeles
}

\author{
A. Muneer, B.Sc., M.B., Ch.B., N. S. Jones, F.R.C.S.
}

\begin{abstract}
Sphenoid sinus mucocoeles can stimulate a variety of pathological conditions and patients can present to a range of specialists. Because of the relative rarity of sphenoid sinus mucocoeles, diagnosis is often delayed and these lesions can progressively expand and cause direct mechanical compression on adjacent structures. We present three cases which presented with an abducens nerve palsy. Early surgical intervention is advocated and these patients' symptoms resolved following surgery. Although several conditions can present with an abducens nerve palsy, it is important to consider a sphenoid sinus mucocoele in the differential diagnosis.
\end{abstract}

Key words: Mucocoele; Sphenoid sinus; Abducens nerve

\section{Introduction}

The incidence of sphenoid sinus mucocoeles is relatively low, with few cases having been reported in the medical literature since Berg (1989) first described them. The sphenoid sinus is a rudimentary cavity at birth which gradually enlarges with development. The ostium is located just lateral to the vomer of the nasal septum $1 \mathrm{~cm}$ above the posteroir choana. Mucocoeles themselves are epithelial-lined lesions containing inspissated mucus, arising as a result of obstruction of the sinus ostium. The obstruction can be the result of inflammation, trauma, congenital anomalies, previous surgery or mass lesions (Moriyama et al., 1992; Natvig and Larson, 1992).

The differential diagnosis of lesions in the area of the sphenoid also includes hypophyseal tumours, craniopharyngiomas, meningioma or glioma, intracranial chordoma, dysgerminoma and cholesteatoma as well as neoplastic lesions of the skull base, sinuses and nasopharynx.

The lesion may extend to affect adjacent structures, giving rise to a variety of clinical manifestations. Headache, facial pain, anosmia, ocular displacement, ocular palsy and visual failure are the commonest symptoms reported. Unusual presentations include hypopituitarism (Valvassori and Putterman, 1973).

We review three cases which initially presented with an abducens nerve palsy.

\section{Case reports}

Case 1

A 32-year-old nurse presented to the neurology department with a one-week history of a frontal headache, rightsided ocular pain and diplopia following an earlier episode of sinusitis. She was previously known to have nasal polyposis and aspirin sensitivity and had undergone an intranasal polypectomy four years previously. On examination she was found to have a right abducens nerve palsy and diplopia with no loss of visual acuity. The remainder of her neurological examination was unremarkable. Haema-

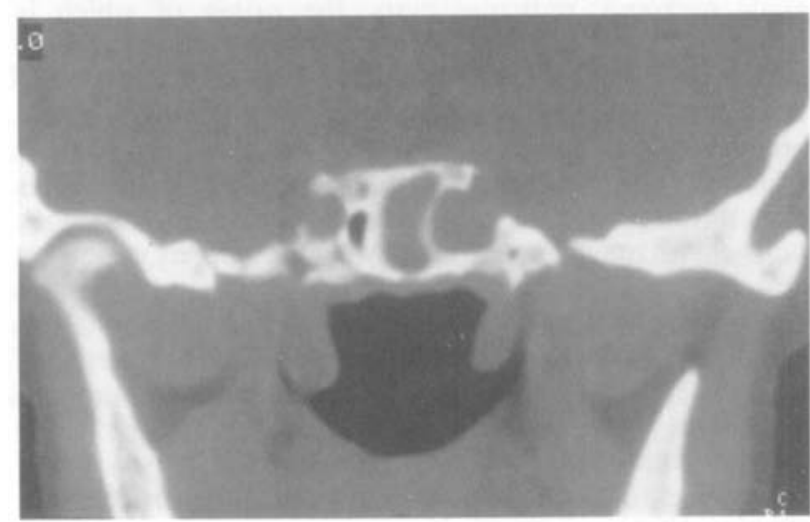

Fig. 1

Computed tomography (CT) scan showing lateral erosion of sphenoid wall by mucocoele.

tological investigations revealed a raised ESR. Computed tomography showed a sphenoid sinus mucocoele with severe polyposis. The lesion had eroded through the lateral wall of the sphenoid (Figure 1). Following a course of antibiotics and oral steroids, her abducens nerve palsy resolved within 48 hours. She subsequently underwent a right endoscopic fronto-spheno-ethmoidectomy and has remained well since.

\section{Case 2}

A 32-year-old sound recordist presented with right-sided periorbital cellulitis and fluctuating anosmia. $\mathrm{He}$ was known to have extensive nasal polyposis and aspirin sensitivity, having had three operations over the previous five years including an intranasal polypectomy and a bilateral external ethmoidectomy. This first episode of cellulitis completely resolved with parenteral antibiotics and he was subsequently discharged. Following discharge he re-presented with a right-sided periorbital cellulitis which again responded to parenteral antibiotics. However, 


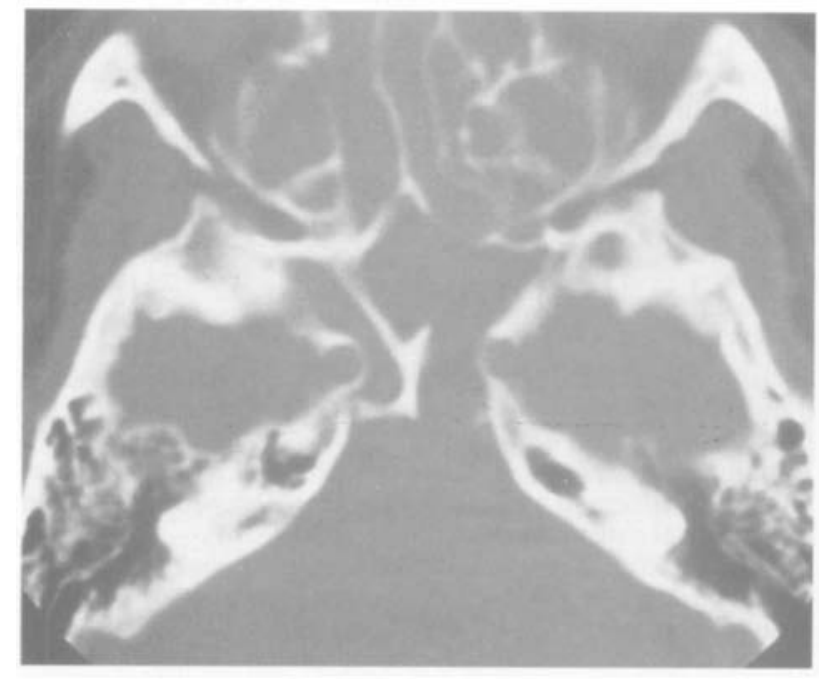

FIG. 2

Axial CT scan showing erosion of the posterior wall due to a sphenoidal mucocoele.

four days later he developed a right abducens nerve palsy and diplopia. There was no other associated neurological deficit. He was subsequently transferred to our department where computed tomography showed a sphenoid sinus mucocoele associated with a deficit in the posterior wall of the sphenoid sinus together with gross polyposis (Figure 2 ). The cranial nerve palsy settled with oral steroids within 48 hours and he underwent a bilateral endoscopic frontospheno-ethmoidectomy and polypectomy.

\section{Case 3}

A 27-year-old teacher sustained a minor head injury as a result of a syncopal episode. Two days later he presented with diplopia. He was known to have severe nasal polyposis and had undergone an intranasal polypectomy two years previously. On examination he had a right-sided abducens nerve palsy and diplopia. The remainder of his neurological examination was unremarkable and there was no change in visual acuity. Computed tomography revealed a homogenous mass occupying the sphenoid sinus and pituitary fossa and extending dorsally toward the pons (Figure 3). A trans-sphenoidal approach revealed

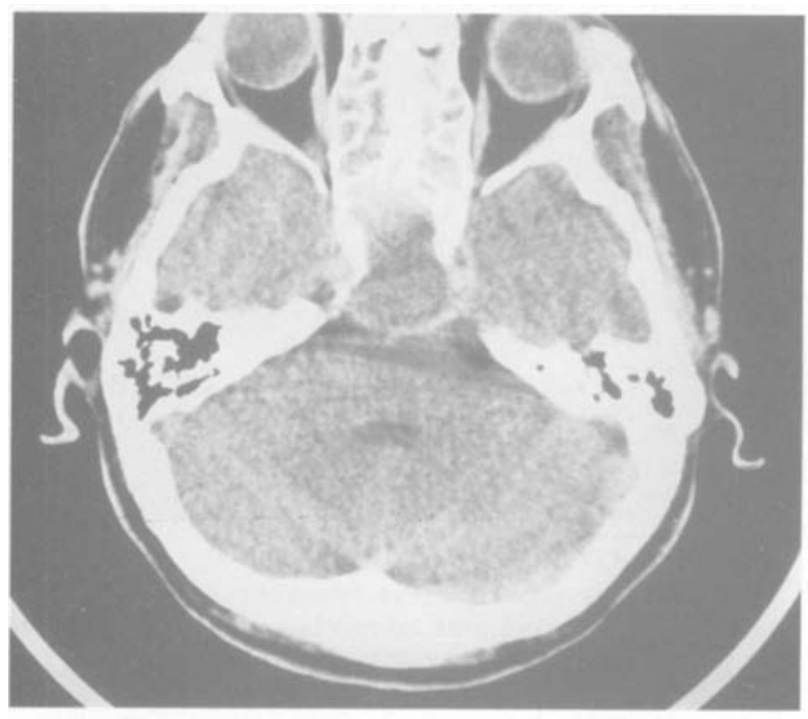

FIG. 3

Axial CT scan showing an expanding sphenoidal mucocoele. that this was a sphenoidal mucocoele and this was marsupialized. His diplopia resolved post-operatively within 24 hours.

\section{Discussion}

Previous reports stated that a consistent complaint associated with sphenoid mucocoeles is a chronic and fluctuating headache which may be frontal, retro-orbital or over the vertex. A retrospective analysis of the presenting symptoms in 63 patients by Nugent et al. (1970) found that headache was present in 45 cases, of which 18 were localized to the frontal region and the remainder described pain in the region of the eye.

Visual symptoms commonly lead patients to seek an ophthalmological opinion. A review of 47 patients by Moriyama et al. (1992) reported that 70 per cent of patients first sought help from the ophthalmology department Visual symptoms include diplopia, ocular muscle paresis, exophthalmos and complete visual loss. Both unilatera and bilateral visual loss have been reported in the literature (McCarthy and Frenkel, 1972; Casteels et al., 1992; Hao, 1994).

Acute blindness secondary to mucocoele expansion is more frequent in adults than children (Casteels et al., 1992). The cause is thought to be direct compression of the optic nerve in the optic canal. However, studies have also shown that the visual loss may be due to a local inflammatory response which responds to steroid therapy (Fujitani et al., 1984). Permanent visual loss secondary to a sphenoid mucocoele is rare, provided that surgery is not significantly delayed.

All three of our patients complained of diplopia during their initial presentation. Characteristically, diplopia occurs at the extremes of gaze and is not disabling enough for the patients to seek a medical opinion early. Diplopia can also occur as a result of globe displacement with intact cranial nerve function. In these cases there was no evidence of ocular displacement and the diplopia is most likely to be due to the abducens nerve palsy. An oculomotor or abducens nerve palsy, either individually or in combination, are the most frequent nerve palsies to present with diplopia (Sellars and De Villiers, 1981).

As there is no exit for the accumulated secretions, gradual expansion of the cavity occurs due to the release of osteolytic prostaglandins and mediators with bony remodelling and erosion (Lund et al., 1988). Eventual compression of surrounding structures results and this is the likely basis for involvement of the cranial nerves.

Involvement of cranial nerves II to VI has been documented previously in association with mucocoeles of the sphenoid sinus (Friedmann and Harrison, 1970; Nugent et al., 1970; Sellars and De Villiers, 1981). Interestingly, previous reports have suggested that pupilsparing oculomotor nerve palsy is the commonest, as opposed to involvement of the other cranial nerves. However, all three of our patients presented with an abducens nerve palsy with no involvement of other cranial nerves.

The abducens nerve has the longest intracranial course of all the cranial nerves and is most liable to stretching injury from expanding intracranial mass lesions. The abducens nerve emerges from the brainstem and ascends anterolaterally through the cisterna pontis along the clivus. The nerve pierces the dura mater lateral to the dorsum sellae. Before passing into the cavernous sinus the abducens nerve lies on the medial tip of the petrous temporal bone where it enters a fibro-osseus canal (Dorello's canal). It then passes horizontally amongst the interstices of the cavernous sinus, initially winding around 
TABLE I

DIFFERENTIAL DIAGNOSIS OF AN ABDUCENS NERVE PALSY

- Brainstem displacement due to supratentoral mass (false localizing sign of raised intracranial pressure)

- Internal carotid artery aneurysm

- Cavernous sinus thrombosis/inferior petrosal sinus thrombosis

- Petrositis due to middle ear and mastoid infection (associated facial paresis with ocular and facial pain constitute Gradenigo's syndrome)

- Dural arterio-venous malformation

- Tolosa-Hunt Syndrome (unilateral ophthalmoplegia with retro-orbital pain)

- Herpes zoster, post-measles infection

- Pontine infarction (with ipsilateral facial palsy and contralateral hemiplegia constitutes Millard-Gublar syndrome)

- Longitudinal fracture of the petrous bone

- Systemic conditions producing a mononeuritis or as part of a mononeuritis multiplex e.g. diabetes, systemic lupus erythematosus, polyarteritis nodosa, multiple sclerosis, sarcoidosis and leprosy.

- Idiopathic or vascular events

- Expanding skull base lesions (nasopharyngeal carcinoma, sphenoid mucocoele, hypophyseal tumours, craniopharyngiomas, paranasal sinus neoplasms)

the lateral aspect of the ascending portion of the internal carotid artery. The abducens, oculomotor and trochlear nerves enter the orbital cavity through the superior orbital fissure. It is the gradual expansion of the mucocoele into the cavernous sinus or superior orbital fissure which directly compresses the abducens nerve. Local inflammation can also be a contributing factor as exemplified by two of our cases which responded to oral steroids. Alternative lesions which can result in an abducens nerve palsy are shown in Table I.

The investigation of choice is computed tomography which will delineate any bony erosion and allow visualization of the anatomy distorted by any previous surgery and pathology. Small areas of bony erosion are not always well seen. Moderate to marked hypointensity (relative to white matter) patterns are seen depending on the degree of hydration of the mucocoele contents. Magnetic resonance imaging (MRI) is rarely necessary but a T1-weighted sequence with, and without, gadolinium can help to differentiate a mucocoele from a neoplastic lesion.

The consensus is that surgical marsupialization is the treatment of choice (Beasley and Jones, 1995; Benninger and Marks, 1995). Endoscopic sinus surgery (ESS) has become an accepted surgical technique for the treatment of paranasal sinus disease and has been efficacious in the treatment of sphenoid sinus mucocoeles (Kennedy, 1985; Lund, 1990; Wigand and Hoseman, 1991). ESS has been advocated for the treatment of mucocoeles, with lower morbidity and a reduction in potential complications compared to intracranial approaches (Lim and Loh, 1992; Hao, 1994; Beasley and Jones, 1995). ESS allows a good visualization of the operative field with minimal blood loss.
The multitude of symptoms and signs and the relative inaccessibility of the sphenoid to clinical examination makes the diagnosis of a sphenoid sinus mucocoele difficult. A sphenoid mucocoele should be considered in the differential diagnosis of a unilateral abducens nerve palsy.

\section{References}

Beasley, N. J. P., Jones, N. S. (1995) Paranasal sinus mucoceles: Modern management. American Journal of Rhinology 9: 251-256.

Benninger, M. S., Mark, S. (1995) The endoscopic management of sphenoid and ethmoid mucocoeles with orbital and intranasal extension. Rhinology 33: 157-161.

Berg, J. (1889) Bidrag till kännedomen om sjukdomarana I näsans bihalor samt till läran om cerebro-spinal-vätskas flytning ur näsam. Nordiskt Medicinskt Arkiv 21: 1-24.

Casteels, F., De Loof, E., Brock, P., Jorrissen, M., Dralands, L., Missotten, L., Wilms, G. (1992) Sudden blindness in a child: Presenting symptoms of a sphenoid sinus mucocoele. British Journal of Ophthalmology 76: 502-504.

Friedman, G., Harrison, M. S. (1970) Mucocoele of the sphenoid sinus as a cause of recent oculator nerve palsy. Journal of Neurology, Neurosurgery and Psychiatry 33: 172.

Fujitani, T., Takahashi, T., Asai, T. (1984) Optic nerve disturbance caused by frontal and fronto-ethmoidal mucopyoceles. Archives of Otolaryngology 110: 257-269.

Hao, S. P. (1994) Mucocele of the sphenoid sinus with acute blindness: report of a case. Journal of the Formosan Medical Association 93(6): 519-521.

Kennedy, D. E. (1985) Functional endoscopic sinus surgery. Archives of Otolaryngology 111: 643-649.

Lim, C. T., Loh, L. E. (1992) Sphenoid mucocoele: detection and surgery by intranasal endoscopy. Singapore Medical Journal 33: 604-606.

Lund, V. J. (1990) Surgery of the ethmoids - past, present and future: a review. Journal of the Royal Society of Medicine 83: 451-455.

Lund, V. J., Harvey, W., Meghji, S., Harris, M. (1988) Prostaglandin synthesis in the pathogenesis of frontoethmoidal mucoceles. Acta Otolaryngologica (Stockholm) 106: 145-151.

McCarthy, W. L., Frenkel, M. (1972) Visual loss as the only symptom of sphenoid sinus mucocele. American Journal of Ophthalmology 74: 1134-1140.

Moriyama, H., Nakajima, T., Honda, Y. (1992) Studies on mucocoeles of the ethmoid and sphenoid sinuses. Analysis of 47 cases. Journal of Laryngology and Otology 106: 23-27.

Natvig, K., Larson, T. E. (1992) Mucocoele of the paranasal sinuses. Journal of Laryngology and Otology 92: 1075-1082.

Nugent, G. R., Sprinkle, P., Bloor, B. M. (1970) Sphenoid sinus mucoceles. Journal of Neurosurgery 72: 443-451.

Sellars, S. L., De Villiers, J. C. (1981) The sphenoid sinus mucocoele. Journal of Laryngology and Otology 95: 493-502.

Valvassori, G. E., Putterman, A. M. (1973) Ophthalmological and radiological findings in sphenoidal mucoceles. Archives of Ophthalmology 90: 416-419.

Wigand, M. E., Hoseman, W. G. (1991) Results of endoscopic surgery of the paranasal sinuses and anterior skull base. Journal of Otolaryngology 20: 385-390.

Address for correspondence:

N. S. Jones,

Department of Otorhinolaryngology, Head and Neck Surgery,

Queen's Medical Centre,

Nottingham NG7 2UH. 